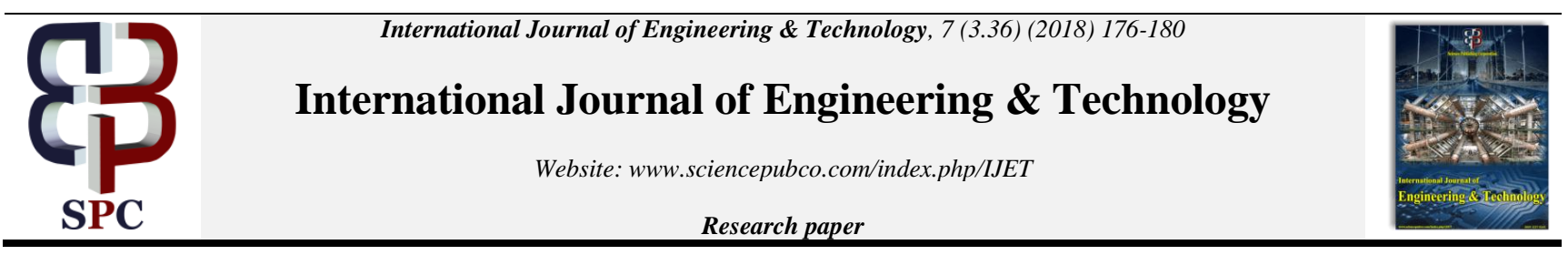

\title{
Influence of Aluminum Mesh electrode on Performance of a Microbial Fuel Cell (MFC)
}

\author{
M. I. N. Ma'arof, Girma T. Chala, and Saravanan a/l Ravichanthiran \\ Department of Mechanical Engineering, Faculty of Engineering and Quantity Surveying, INTI International University, \\ Persiaran Perdana BBN, Putra Nilai, 71800 Nilai, Negeri Sembilan
}

\begin{abstract}
Recently, various steps have been taken to utilize and develop renewable and sustainable form of energies due to the negative impact and dire limitation over continuous dependency on fossil fuel. This paper presents the effects of aluminium mesh on the performance of a MFC. Aluminium mesh with rectangular shape was used as the electrode and experiments were conducted with respect to various types of resistors. The amount of voltages and power density generated were determined. It was found that the increase in bacterial activities resulted in the increment of oxygen supply, therefore, the voltage generated also increased. In addition, the longevity of bacterial activity is dependent on the amount of catalyst. Moreover, it was observed that the performance of aluminium mesh electrode was smaller than that of graphite electrode.
\end{abstract}

Keywords: microbial fuel cell; aluminium mesh; open circuit voltage; sustainable energy

\section{Introduction}

The Microbial Fuel Cells (MFC) is a sustainable and renewable fuel cell where the system utilizes oxidation reactions to produce electricity by making via chemical energy $[1,2]$. MFC comprises of a cathode, an anode and a membrane [3-5]. The anode and cathode compartments are divided by the membrane which is cation specific. At the anode, organic fuel generating protons are oxidized by microbes and then move across the membrane to the cathode. From anode to outer circuit, the electrons are also oxidized by microbes to generate current [6].

MFC relies on living biocatalysts to facilitate the movement of electrons in the system [7]. Microbes are unable to move electrons directly to the cathode except if the species located in the anode compartment are anodophiles. Most microbial species consist of an outer layer comprising of lipopolysaccharides, lipid membrane and peptididoglycans. Henceforth, due to this, direct transfer to the anode is obstructed. Hence, electron mediators were utilized in order to increase the rate of electron transfer [8].

The respiration of bacteria results in the redox reaction that causes for electron movement, and this produces electromotive force. When electrons found within the membrane are taken, oxidized state mediators can be diminished. The mediators then move from cathode to the anode via the membrane to release electrons in order to get oxidized again in the anode compartment. This action increases the rate of transfer of electrons which eventually rises the power output. Although theory states that a mediator with lowest redox would result in the lowest anodic redox (resulting in a widening gap between the electrodes), it is however not the most systematic method of getting electrons away from reduced intracellular systems found within microbes [9]. Therefore, as compared to a mediator with lower redox, a mediator having more Eo redox is bound to give out more power overall. Although typical synthetics exogenous mediators consist of metal organics and dyes such as Fe (III) EDTA, methylene Blue (MB) and Neutral Red (NR), these mediators are unfortunately cannot be used for MFC due to their instability and toxicity. Even so, certain natural compounds such as microbial metabolites can be used as mediators by microbes. Oxyanions of sulphur (sulphate and thiosulphate), Humic acids and anthraquinone are all having the potential of transferring electrons found within the cell membrane to the anode [10].

On the surface of the anode, the microbes produce a biofilm where electrons are transferred through the membrane via conductance (11 ). In the biofilms, when these microbes are used, in the dissimilatory respiratory chain, the final electron acceptor is denoted by the anode. On the cathode surface, biofilms are formed which are essential for the electron transfer between the electrodes and microbes. Unfortunately, due to the complications associated to a simplified design which would allow poor rural residents to build it, MFCs are still in pilot stages in third world countries. As reported in earlier research, a MFC is a useful technology and more interest should be generated towards its development. The objective of this paper is to investigate the influence of aluminium electrode on the performance of Microbial Fuel Cell (MFC).

\section{Experimental setup and procedures}

\subsection{Experimental setup and the feeding system}

A double chamber microbial fuel cell was constructed. By being mediator-less, the MFC does require for the use of a mediator to carry the electrons across the Proton-Exchange Membrane (PE). In this study, the aluminium mesh with rectangular shape was utilized as the electrode, instead of the graphite electrode which was used by Muhammad Izzat et al. [12]. The materials used include Anode and Cathode Containers, two plastic containers with sealable lids, acrylic, safety goggles, drill, mud, air pump, sealing materials epoxy, different Resistors, digital Multimeter, Aluminium mesh electrodes, and copper wire. 
The feeding system delivers a constant supply of food to the bacteria without the need for additional external power unit. The feed tank was sealed tightly in a vacuum, while the other chamber that contains water was exposed to the environment. The feed tank was allocated above the anode compartments facilitating for the siphoning activity to take place and delivering food and nutrition to the chamber. The waste from the anode chamber was collected by the waste tank located underneath. A check valve was also installed to prevent the backflow of the solution from the water tank to the anode compartments and same goes to the anode compartment to the feed tank. As the anode chamber was sealed tightly in for a range of time, it allows a perfect biofilm to form. Furthermore, the anode must be in the state of vacuum and absent with any sort of contaminants. Figure 1 shows the schematic diagram of the experimental setup.

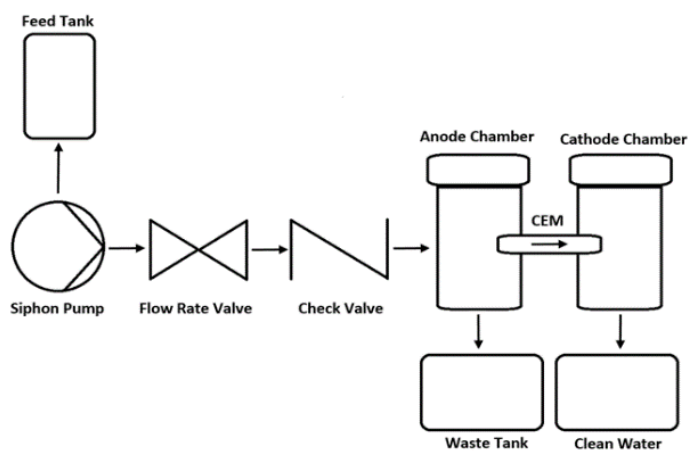

Fig. 1: Experimental setup

\subsection{The MFC's Ion Exchange Membrane}

The two separate chambers of the MFC are conventionally separated via a 'bridge' known as the Cation Exchange Membrane (CEM). The design configurations of the CEM is generally dependent on the fuel cell, Cation Exchange Membranes, Anion Exchange Membrane and the Proton Exchange Membrane. The main purpose of the CEM is to allow for ion exchange. For the Proton Exchange Membrane, the CEM allows for the hydrogen ion to pass through anode and cathode so that the hydrogen ion will be combining with the oxygen, and forms water molecules. The CEM was incorporated with the mixture of salt and 'agaragar'. In addition, the membrane used for experiment was the Nafion 117 membrane. The Nafion 117 was selected because it is more robust and thicker in comparison to Ultex. Furthermore, the Nafion 117 could resist from any chemical reaction, and it is impermeable to water.

\subsection{Experimental Procedure}

Two (2) separate cable wires were connected to each end of a resistor. One end of a resistor was connected to the cathode end, whilst the other end was connected to the anode. At the cathode chamber, an air pump was connected to supply oxygen to the system. At the anode chamber, the external circuit was completed for the electron to move from one side to another. Finally, the open circuit voltage in between the anode and cathode were recorded using a multi-meter for data collection. Upon completion of data collection, different types of resistors were tested over a range of time.

\subsection{Data Collection and Analysis}

The overall voltage that could be produced by the MFC can be determined as follows. Nevertheless, the actual output produced by the MFV requires for the subtraction from the maximum EMF once the optimal cell EMD is determined [13].

$$
\text { Eemf }=E^{0} \text { emf }-\left\{\frac{R T}{8 F} x \ln (\pi)\right\}
$$

Where: $\mathrm{R}=8.31447 \mathrm{~mol}-1 \mathrm{~K}-1$, the universal gas constant, $\mathrm{T}=$ the optimal temperature in kelvin at which values are recorded and, $F=9.64853 \mathrm{C} / \mathrm{mol}-1$, Faraday's constant and $\Pi$ is the ratio of product activities to the reactants from each chemical reaction. Since this equation is used to gain the EMF for the anode and cathode separately, it has to be used twice. Since two different reactions take place in the anode and cathode, the two different EMF values for the anode and cathode, Eanode and Ecathode have to be deducted to achieve the overall system EMF.

$$
\text { Emfc }=\text { Ecathode }- \text { Eanode }
$$

When the EMF of the anode and cathode are subtracted, it denotes the value of the voltage - the potential difference between the two. From the above, the total Eemf can be written in a more general form of the final voltage equation.

$$
\text { Ecell }=O V C-I R_{\text {int }}
$$

In this study, the data collected were: (i) power, (ii) current density, and (iii) power density.

Surface area of each electrode was calculated as follows:

$$
A=W x H x L
$$

Where: Width $=53 \mathrm{~mm}$, Height $=1.4 \mathrm{~mm}$ and Length $=70 \mathrm{~mm}$

Power, $\mathrm{P}=$ Voltage $(\mathrm{V}) \times$ Current (I)

Current density $=\frac{\text { current }(\mathrm{I})}{\text { anodic area }\left(\mathrm{mm}^{2}\right)}$

Power Density $=\frac{\text { power }}{\text { anodic area }\left(\mathrm{mm}^{2}\right)}$

\section{Results \& Discussion}

Power input was recorded at regular time intervals. The selected resistors were $16 \mathrm{k}$ Ohms, $5 \mathrm{k}$ Ohms, $2.5 \mathrm{k}$ Ohms, $1 \mathrm{k}$ Ohms and 100 Ohms. Voltages and currents readings were taken three times to get average reading to minimize the random error. This way could increase the accuracy of the result obtained for the experiment. Figure 2 shows voltages values over ten days period.

In utilizing the aluminium mesh, it was apparent that from day 1 until day 3 , the amount of voltage was increasing in a constant rate from $0.15 \mathrm{~V}$ to $0.45 \mathrm{~V}$. The anode chamber that contains the organic substance (which for this case was mud) was observed to release heat as water vapors were visible at the wall of the compartment. This was because mud is dense, compact and able to absorb heat from the surrounding, facilitating the growth of bacteria.

From day 4 until day 6 , it was observed that the reading was increasing rapidly from $0.55 \mathrm{~V}$ to $0.91 \mathrm{~V}$. The reading at the $6^{\text {th }}$ day was the highest reading obtained during the 6 days period. The sudden increase in voltage was caused by the bacteria activity in the anode chamber. As there was catalyst, the bacterial activities increased, and this eventually caused more positive electrons go through from anode to cathode to produce electricity. The anode chamber was undergoing same process as the heat released from the mud caused the wall of the compartment to be covered with water vapor. As for the cathode chamber, the water turns into different color which was slight orange color. It was due to the Cation Exchange Membrane (CEM) which was filled with colored agar-agar in orange color. Therefore, the color of water changes due to the agar-agar as it was in concentrated orange color that eventually mix with the water.

There was a decreasing trend observed from day 6 until day 10: from $0.91 \mathrm{~V}$ to $0.59 \mathrm{~V}$. The bacteria activity was affected due to the catalyst, since the catalyst was depleting due to the consumption of agar-agar by the bacteria as food. The transfer of cation from the bacteria was decreasing, and this causes the voltage to drop across anode and cathode compartment. In addition, it is also pos- 
sible that there was less oxygen for the whole system to undergo very efficient process. Therefore, with higher percentage of oxygen in cathode chamber, the electrons can be activated and cause the hike in reading of the voltage. Furthermore, the anode chamber was observed as to exhibit no more water vapor on the wall as all the heat in the mud releases. The moisture of the mud was less since it was placed outdoor and exposed to the sun. As for the cathode chamber, the color of the water, which was originally slight orange, changes to slightly darker orange and can be considered as chalky in color.

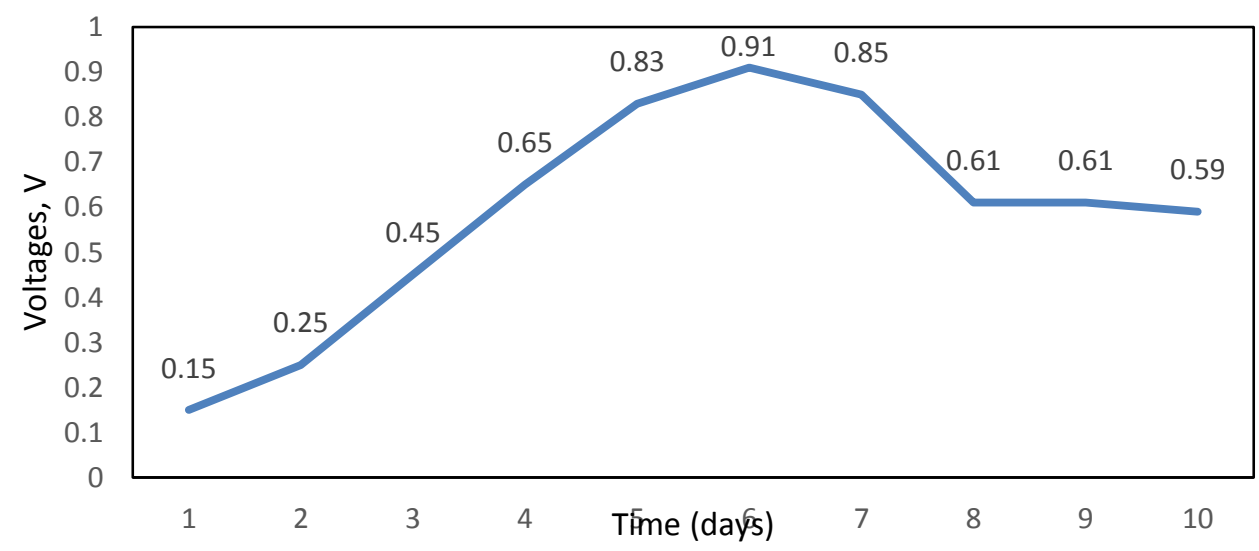

Fig. 2: Open circuit voltage over 10 days period for Aluminium mesh electrode

Figure 3 shows voltage against current for different resistors for a period of 10 days. It can be seen that the trend of the graph was increasing steadily and reached its peak at $6^{\text {th }}$ day. It was due to the number of bacteria present in the system where the bacteria required certain time of period to form the anodic biofilm. Follow- ing that, it declined from $6^{\text {th }}$ day onwards till the $10^{\text {th }}$ day. It was because the catalyst in the system was decreasing as the days passed along. This could be due to the decrement in the substrate concentration.

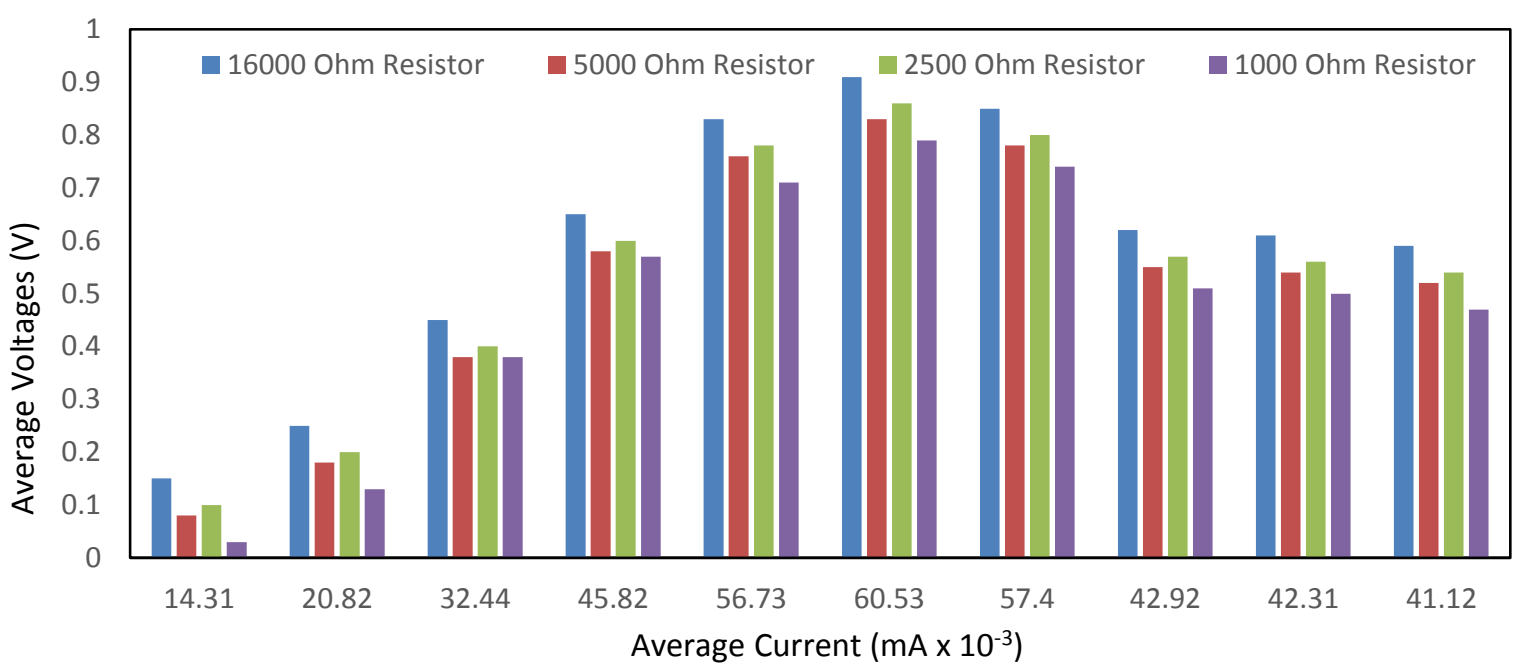

Fig. 3: Voltage versus current with various resistors for 10 days period for Aluminium mesh electrode

Figure 4 shows power over 10 days period for aluminium mesh. It can be seen that $0.1 \mathrm{k}$ Ohm has the highest power and $16 \mathrm{k}$ Ohms has the lowest power among the other resistors. When a large number of resistant was attached as a load to the system, a large amount of voltage was produced from the system. However, the production of the current was relatively small. If a small number of resistant was attached as a load to the system, the voltage produced across the compartment would be low compared to the current where it will be a maximum produced. Therefore, the power obtained from the system would be high but for certain period of time.

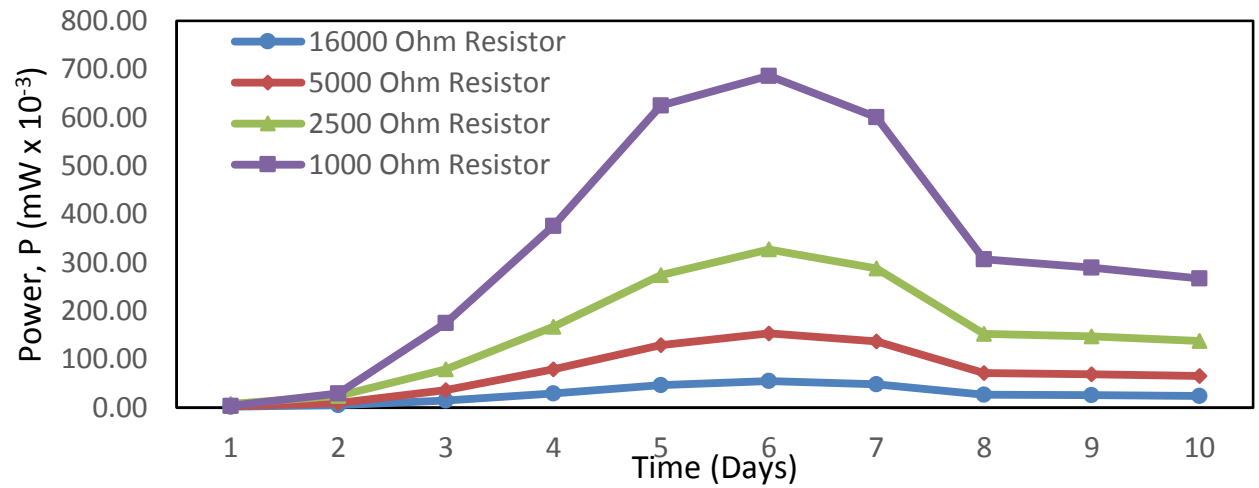

Fig. 4: Power over 10 days period for Aluminium mesh electrode 
Figure 5 shows the polynomial equation for Aluminium Mesh electrode. The purpose of using the polynomial equation was to discover the period for the electron movement to completely stop transferring across both chamber in the system. If there is no flow of electrons from anode compartment towards the cathode com- partment, there would be no electricity produced. Therefore, to find the period for the electron movement completely disappear or stop transferring in the system, it was mathematically estimated using different kind of resistors.

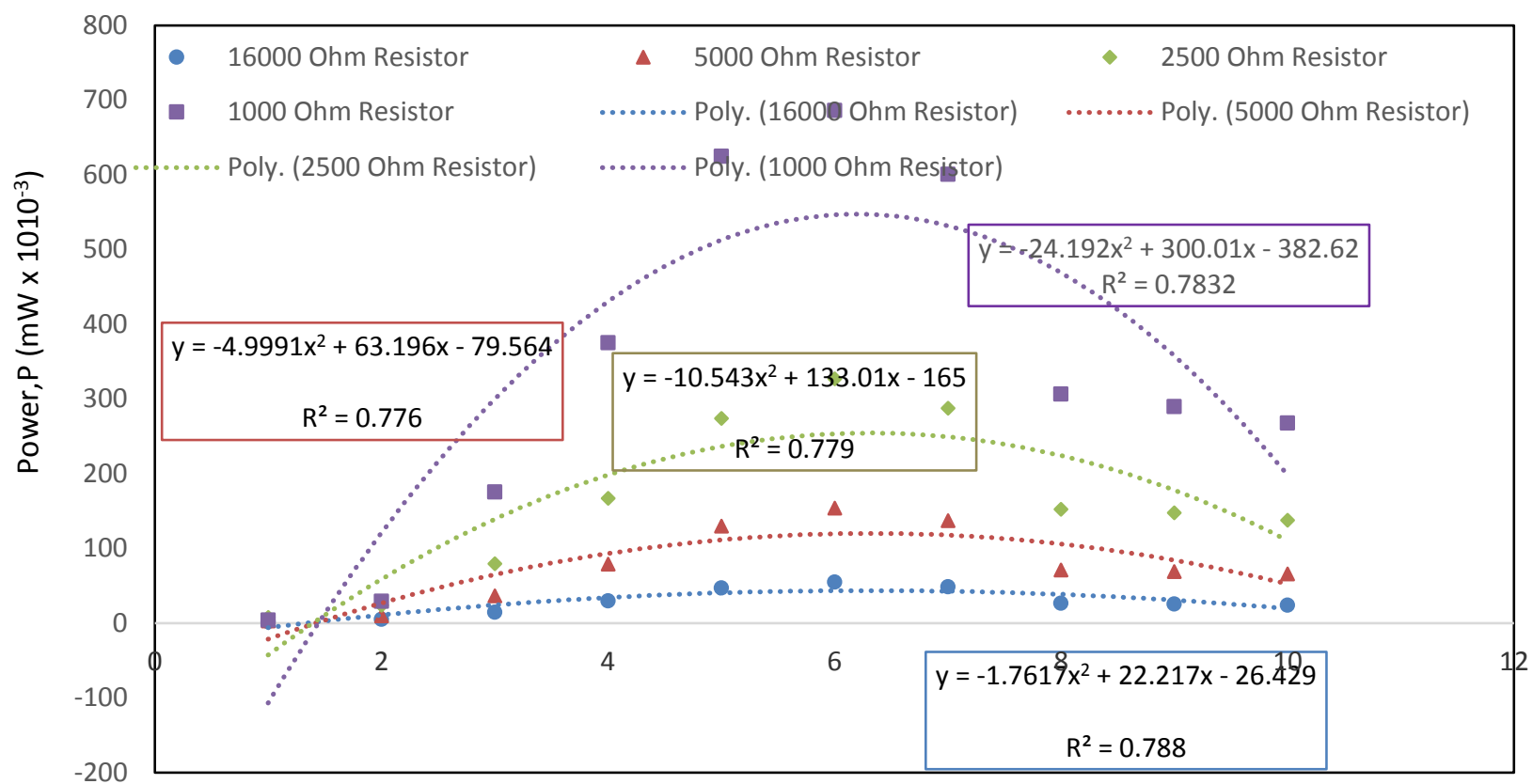

Time (Days)

Fig. 5: Power against 10 days period together with polynomial equations for Aluminium mesh

The movement of electron to stop in the system can be predicted using polynomial equations. Table 1 depicts polynomial equations for different resistors. It can be seen that different resistors give different period for electron to stop transferring as they might not be enough catalyst for the bacteria to live in the system. For $16 \mathrm{k}$ $\mathrm{Ohm}, 5 \mathrm{k} \mathrm{Ohm}, 2.5 \mathrm{k} \mathrm{Ohm}$ and $1 \mathrm{k}$ Ohm resistors, the periods of electron transfer were 11.28 days, 11.22 days, 11.22 days and 10.95 days, respectively. However, there were some amount of voltage present on the $20^{\text {th }}$ day and $24^{\text {th }}$ day which were $0.174 \mathrm{~V}$ and $0.103 \mathrm{~V}$. Therefore, hypothesis can be made where the period for electron to stop transferring is independent on the resistors across both chambers. In short, the electron was not fully cleared from the system as there are certain potential for it to be gone from the system. If the bacteria still exists in the system and there are some catalyst, it still has potential for the electron to be transferring across the system for a long period of time.

Table 1: The period for electron to stop transferring for Aluminium Mesh electrode

\begin{tabular}{|l|l|l|}
\hline Resistors Used, Ohm $(\Omega)$ & Polynomial Equations & Period for electron to stop transferring, (Days) \\
\hline $16 \mathrm{k}$ & $\mathrm{y}=-1.7617 \mathrm{x}^{2}+22.217 \mathrm{x}-26.429$ & 11.28 \\
\hline $5 \mathrm{k}$ & $\mathrm{y}=-4.9991 \mathrm{x}^{2}+63.196 \mathrm{x}-79.564$ & 11.22 \\
\hline $2.5 \mathrm{k}$ & $\mathrm{y}=-10.543 \mathrm{x}^{2}+133.01 \mathrm{x}-165$ & 11.22 \\
\hline $1 \mathrm{k}$ & $\mathrm{y}=-24.192 \mathrm{x}^{2}+300.01 \mathrm{x}-382.62$ & 10.95 \\
\hline
\end{tabular}

\section{Conclusion}

This paper investigated the influence of aluminium mesh electrode on the performance of MFC. The MFC was fabricated by following a well-documented procedures. The following parameters are directly proportional to one another: voltage produced, bacteria activities and the existent/supply of catalyst. In addition, if bacteria remains to exist in the system, it still has potential for the electron to be transferring across the system for a long period of time. Moreover, it was observed that the performance of aluminium mesh electrode was lower than that of graphite electrode. The MFC is a promising sustainable energy, therefore, it is highly recommended for Malaysia to utilize this form of clean and green energy in the near future.

\section{References}

[1] Altenergymag.com. (2017). Microbial Fuel Cells - Principles and Applications | AltEnergyMag. [online] Available at: https://www.altenergymag.com/content.php?post_type=1424 [Accessed 14 Nov. 2017].

[2] Yong, Y. C., Dong, X. C., Chan-Park, M. B., Song, H., \& Chen, P. (2012). Macroporous and monolithic anode based on polyaniline hybridized three-dimensional graphene for high-performance microbial fuel cells. ACS nano, 6(3), 2394-2400.

[3] Tommasi, Tonia, and Giorgia Lombardelli. "Energy sustainability of Microbial Fuel Cell (MFC): A case study." Journal of Power Sources 356 (2017): 438-447.

[4] Khalili, Hajie-Banoo, Davod Mohebbi-Kalhori, and Mahdi Shafiee Afarani. "Microbial fuel cell (MFC) using commercially available unglazed ceramic wares: Low-cost ceramic separators suitable for scale-up." International Journal of Hydrogen Energy 42.12 (2017): 8233-8241. 
[5] Samrat, M. N., Rao, K. K., Ruggeri, B., \& Tommasi, T. (2018) Denitrification of water in a microbial fuel cell (MFC) using seawater bacteria. Journal of Cleaner Production, 178, 449-456.

[6] Illumin.usc.edu. (2017). Illumin - Microbial Fuel Cells: Generating Power from Waste. [online] Available at http://illumin.usc.edu/134/microbial-fuel-cells-generating-powerfrom-waste/ [Accessed 14 Nov. 2017].

[7] Parkash, Anand. Microbial fuel cells: a source of bioenergy. J Microb Biochem Technol 8 (2016): 247-255.

[8] Davis, Frank, and Séamus PJ Higson. "Biofuel cells-recent advances and applications." Biosensors and Bioelectronics22.7 (2007): 1224-1235.

[9] K. Rabaey, et al., "A microbial fuel cell capable of converting glucose to electricity at high rate and efficiency," Biotechnol. Lett., vol. 25, pp. 1531-1535, 2003.

[10] Park, D.H. and Zeikus, J.G. -2003 Improved fuel cell and electrode designs for producing electricity from microbial degradation. Biotechnol. Bioeng. 81, 348-355.

[11] Chaudhuri, Swades K., and Derek R. Lovley. "Electricity generation by direct oxidation of glucose in mediatorless microbial fuel cells." Nature biotechnology 21.10 (2003): 1229.

[12] M. I. N. Ma'arof, Girma T. Chala, Saravanan a/l Ravichanthiran, and Abigail F. Diasip, A Study on Microbial Fuel Cell (Mfc) with Graphite Electrode to Power Underwater Monitoring Devices, International Journal of Mechanical Engineering and Technology, 9(9), 2018, pp. 98-105.

[13] Logan B.E., J.M. 49 Regan. "Feature Article: Microbial fuel cellschallenges and applications." World Bank, 2006. 